Journal of Sustainable and Manufacturing in Transportation

\title{
Development of Computational Model of Motorcycle and Rider during Collision
}

\author{
Aziz Fathurrahman Arwardy ${ }^{1}$, Zaleha Mohamad ${ }^{1 *}$ \\ ${ }^{1}$ Faculty of Mechanical and Manufacturing Engineering, \\ Universiti Tun Hussein Onn Malaysia, Parit Raja, 86400, MALAYSIA \\ *Corresponding Author \\ DOI: https://doi.org/10.30880/jsmt.2021.01.01.005 \\ Received 24 August 2021; Accepted 11 October 2021; Available online 15 December 2021
}

\begin{abstract}
The goal of this project is to develop the computational model of motorcycle and rider for deformable body. Also, to identify the response of rider and motorcycle on collision. Computational model is the one method that can replace the actual experiment on crash test. From the simulation can save cost by actual impact crash test. This project begins with design the model of actual motorcycle. Because the model of the project using Honda Wave 100R is to complex and the computer not powerful enough to generate mesh the simplified model is use for the project. Then, the material of this project using ANSI 304 stainless steel. The simulation of the experiment run by the ANSYS software to calculate mathematical model result after impact. Finally, the result of deformation was recorded to compare the result of deformation on actual crash test. The Comparison result of deformation actual and simulation are quietly similar
\end{abstract}

Keywords: Computational model, collision, deformable

\section{Introduction}

Motorcycle was most common used in some developing and small countries especially in Asia because the condition of small road its easy motorcycle to move from other location to the other location easily (Abdul Manan \& Várhelyi, 2012). The motorcycle has a high potential of accident because the condition of motorcycle that have only two wheel that have low stability control. While motorcycling offers the favorable features, it also comes disadvantages that mainly associated with vulnerability of the motorcyclists. Motorcycle riders are categorized as vulnerable road users alongside with bicyclists and pedestrians. Due to the absence of the protective cage and with almost the only protection afforded to a rider and pillion is the helmet. This coupled with the agile maneuvers the motorcycle can perform due to its single-track design and its stability being more sensitive to environment condition and also lack of protection to the motorcyclist (RoSPA, 2017).The objective of this research is to develop the computational model of motorcycle and rider for deformable body and to investigate the displacement of rider in different velocity during collision

\section{Methodology}

On this section, it will clarify more about the processes undertaken in this research. The aim of all the processes involved is to achieve the objective and ensure smooth running of this study. The main objective of this work was to develop the computational model of motorcycle and rider for deformable body and identify the response of rider on collision.

In this research, there have several processes to complete. The main of this were design the model of motorcycle and rider for deformable body by used the solid works. Then convert to workbench by ANSYS to generate the mesh of 
the motorcycle and rider. The selected problem type was explicit dynamic problem type. Then the simulation run to generate the force acting the motorcycle and rider. Then the result was analyse.

\subsection{Motorcycle and Rider}

The model of motorcycle that has been selected is a model call Honda wave 100r. It is shown in Fig.1. This is a small model motorcycle which is produce by Honda motor company in Japan for ASEAN market. This model of motorcycle is small, cheap and high speed.

a

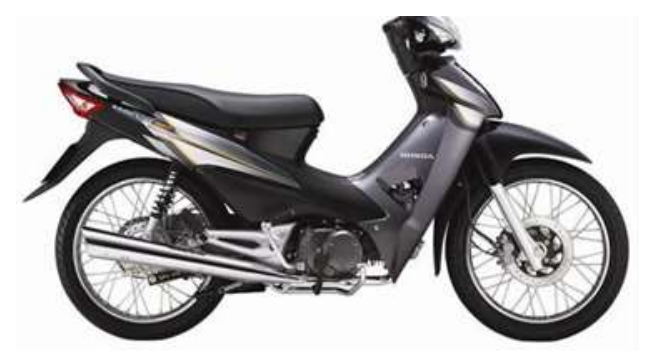

b

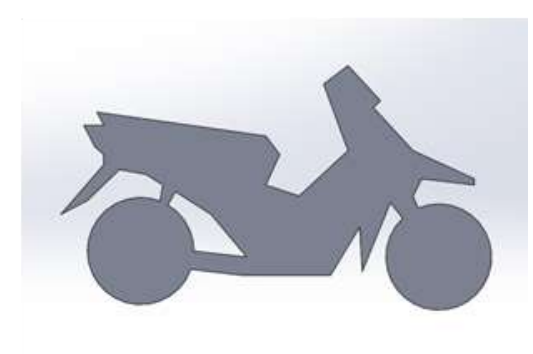

Fig. 1 - (a) Honda wave 100r actual; (b) simulation

The dummy rider model are full scale anthropomorphic test devices that simulate the dimensions, weight proportions and articulation of the human body are usually instrumented to record data about the dynamic behaviour of the ATD in simulated motorcycle impacts. Dummy rider is created to research the effects of frontal impacts and is less valuable in assessing the effects of other sorts of impacts, such as side impacts, rear impacts or rollovers. The Fig. 2 is shown as a model of dummy rider.

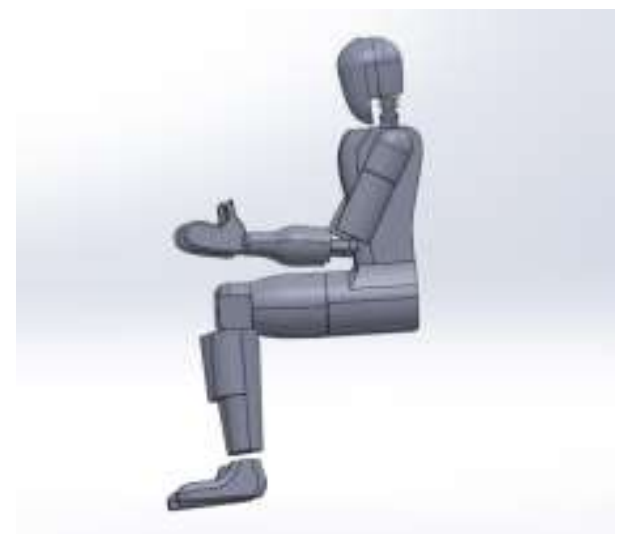

Fig. 2 - A model of dummy rider

The motorcycle and rider are drawing by utilize the solid works software. Then the drawing is export to ANSYS software call as pre-processing and to generated meshing. Before generating the mesh, the meshing is control as well. Besides that, the model of the motorcycle and rider are simplified by reduced the simple model. Finally, the motorcycle and model are inserted the boundary condition and material properties. The Fig. 3 is shown as simple model of motorcycle in meshing condition Procedures can be described using flowcharts and algorithms. Include the appropriate references to standards. Authors can also explain the scope and limitations of the methods. 


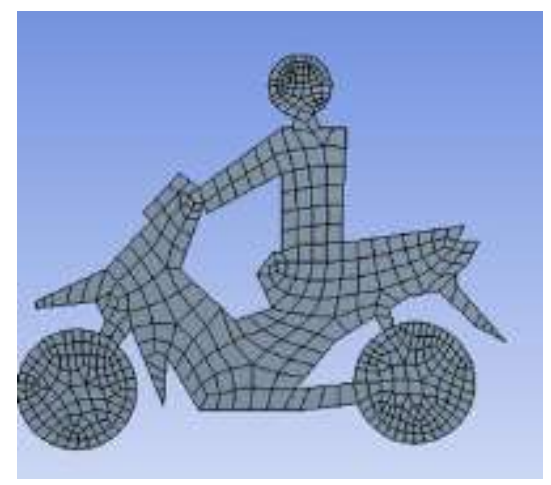

Fig. 3 - Simple model of motorcycle and rider in meshing condition

According to the simple model of motorcycle and rider, the meshing is reducing become 3533 elements and 5218 nodes. So, the time of running simulation is also reduced. The body of motorcycle is set in constraint velocity $13.4 \mathrm{~m} / \mathrm{s}$ as standard velocity (ISO/CD 13232). Thus, the nodes of the of the body motorcycle are assigned in master mode. The material of the body motorcycle in ANSI 304 stainless steel.

\subsection{Wall}

The wall is created to test the reactions of the dummy with motorcycle while Impact to its. The wall is no deformation, so the wall is assigned in boundary condition with zero velocity in all direction. The material of the wall is contact triangle. Fig. 4 shows the simulation test between the wall and the dummy rider with motorcycle.

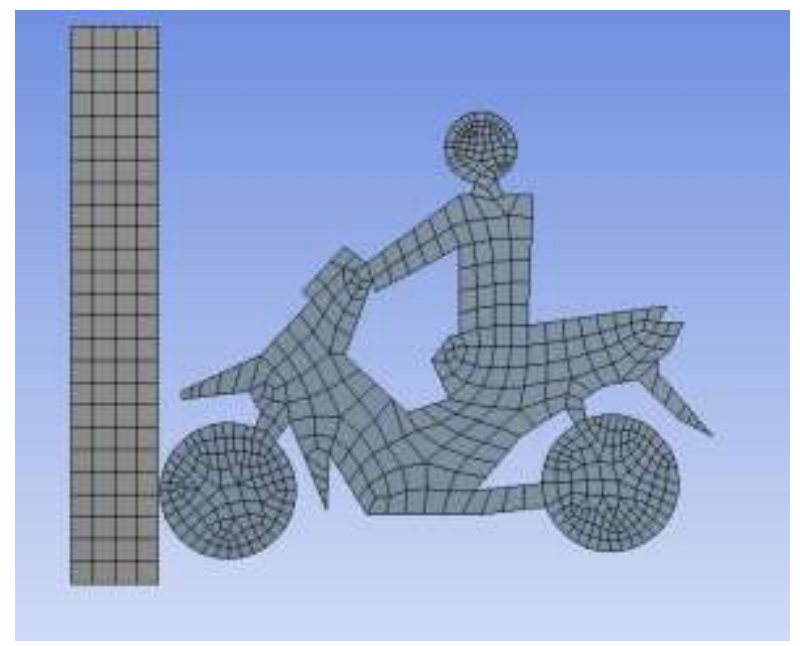

Fig. 4 - The simulation test between the wall and the dummy rider with motorcycle

\subsection{Space Claim and Mechanical}

The Space claim is a cad system that features the widely used NURBS surface for the geometry definition. Typically, geometrical operations can be used as transformation, translations, rotations, Boolean operation in surface and volume. After the completed model of motorcycle and dummy rider, the models are import to ANSYS software to generate the mesh.

Ansys Mechanical is a finite element code which is based on an explicit time stepping algorithm. These kinds of code are used to simulate dynamic phenomena involving large deformations such as car crashes. Impact is designed to be compatible with the ANSYS the program used to make a model and to look at the results after impact has simulated the problem.

\subsection{Computer Simulation}

Multibody dynamics (MBD) and finite element method are consisting in pre-processor. Insert the properties and boundary condition.

The solution process is made in three stages: 
1. Solid work was used to create the model.

2. Then model was insert into workbench by importing to mechanical.

3. The model then were mesh and the animation show the result

After the simulation, the data of graph displacement versus time is taken out from the impact graph section. The body landing and crash behaviour is analysed. According to the graph shape, see the fatal part of motorcycle and rider. The displacement of the motorcycle and rider are signified the movement of the kinematic motorcycle and dummy rider. During the crash, that different displacement is occurred the different part of the dummy rider. Thus, the displacement landing of each part of the dummy rider is become different. According to the graph displacement modelling of each part rider (hybrid body), define the fatal part of the rider. The fatal part of the rider is analysed. So, safety measures can apply on the most critical fatal part to prevent the injury

\section{Result and Discussion}

During the impact, the body rider is connected with motorcycle. Because the motorcycle is moving but not the rider. So that the velocity is applied at the motorcycle. Naturally. The velocity of the rider is pulled by motorcycle when the motorcycle is running. The influences factor of the environment to the velocity between motorcycle and rider are ignored. The influences factor such as friction air, inertial velocity and wind surrounding. Thus, the velocity of motorcycle and the velocity of rider are the same. According to the ISO/CD 13232, the standard velocity is $13.4 \mathrm{~m} / \mathrm{s}$. In motorcycle, the part of wheel is applied in boundary condition and other parts of motorcycle are applied in rigid body. The rider is made in deformable body and every part is connected with the line or call as joint.

Fig. 5 - Sequence of motorcycle impacting actual and simulation

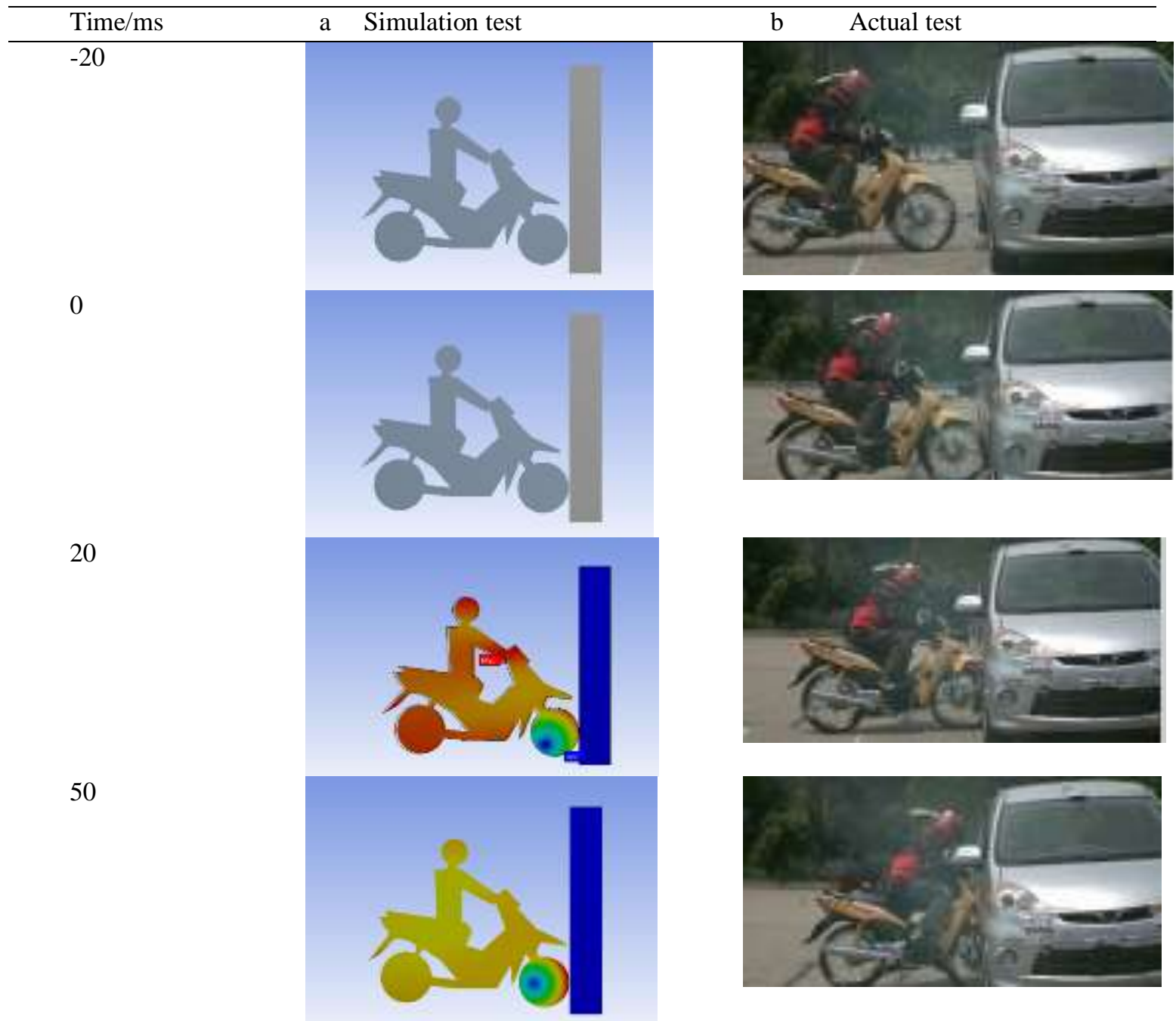


1009

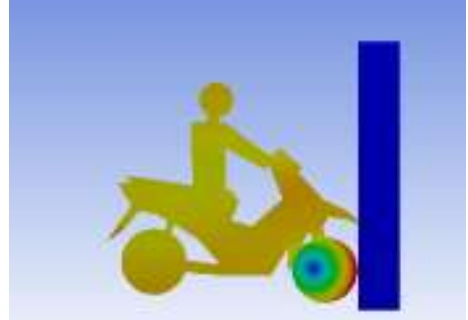

130

350

640

700
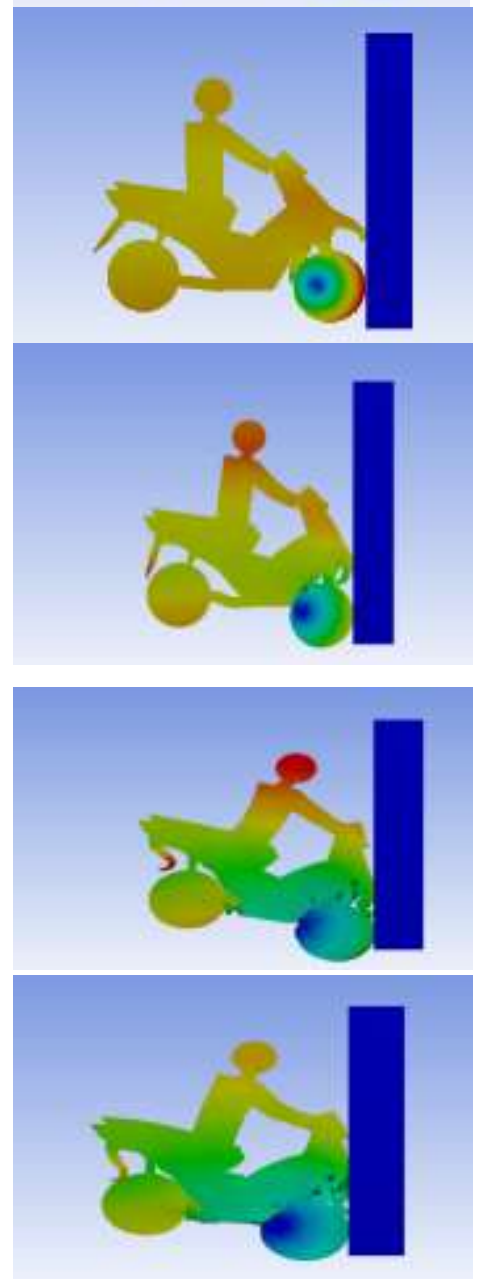
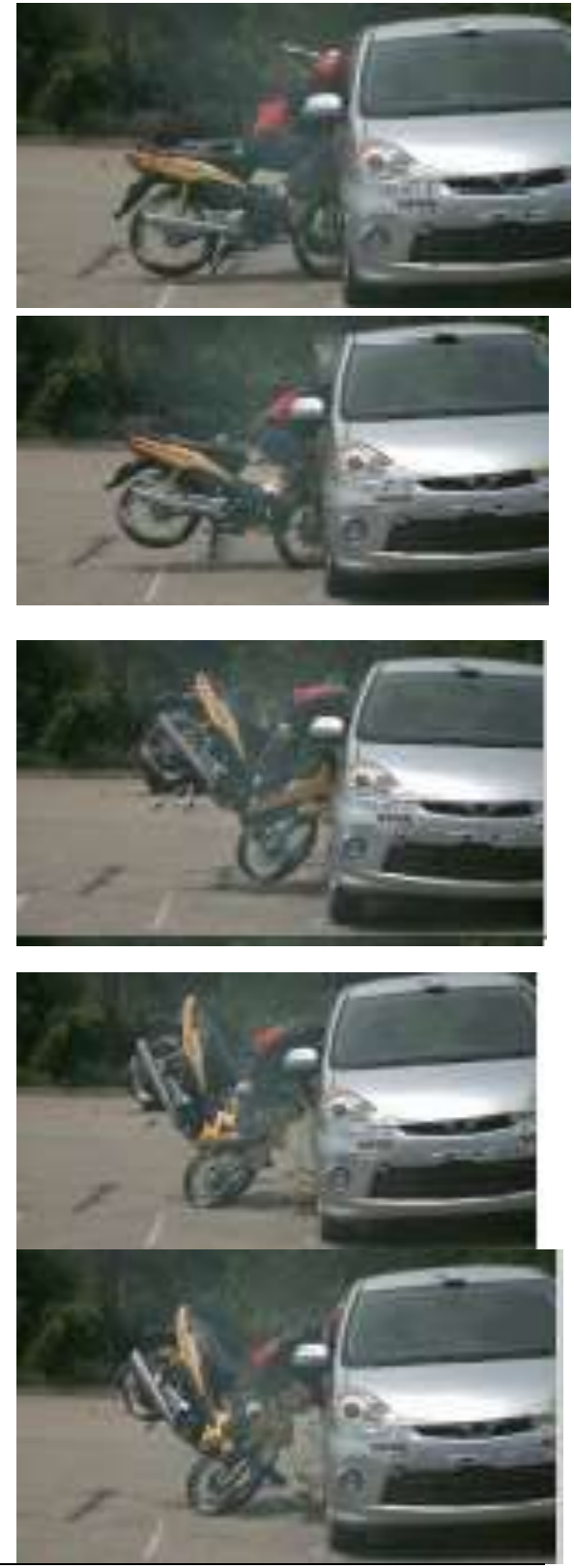

According to the Fig. 6 sequence of motorcycle impacting actual and simulation. The observation between the actual and simulation remains that motorcycle and rider did not contact the wall at $-20 \mathrm{~ms}$ until $0 \mathrm{~ms}$. Then, the front wheel started to deform, and the front suspension began to deflect inward at $20 \mathrm{~ms}$ for booth test. Next, the front wheel and the suspension experienced maximum crush and the rear suspension springs begin to expand and the rider slide forward at $50 \mathrm{~ms}$. After that, the rear wheel began to lift and the rider slide to maximum distance with lower extremities hitting at $100 \mathrm{~ms}$. Then, the wheel rotation increased, and the rider abdomen pivoted around the handlebar at $130 \mathrm{~ms}$. Next, the motorcycle rotated completely off the ground at $350 \mathrm{~ms}$. After that, the motorcycle rotated to the maximum height as the front wheel subsequently hit the ground at $640 \mathrm{~ms}$. Finally, the motorcycle started to drop to the ground at $700 \mathrm{~ms}$. The crash kinematic result showed in Figure 6 was quietly similar to previous research result which is up to 700 ms timeline (Hamzah et. al (2014).

\subsection{Result of Dummy Rider with Motorcycle Simulation}

Test 1 simulation were conducted to test the dummy with motorcycle. The velocity $5.6 \mathrm{~m} / \mathrm{s}$ or $20 \mathrm{~km} / \mathrm{h}$ is applied to the body motorcycle and the dummy at z-direction for duration is from $0 \mathrm{~ms}$ to $4 \mathrm{~ms}$ and been recorded for every $1 \mathrm{~ms}$ for seen the displacement which happen during impact. Fig.6 shows the simulation of dummy with motorcycle in velocity $5.6 \mathrm{~m} / \mathrm{s}$. 


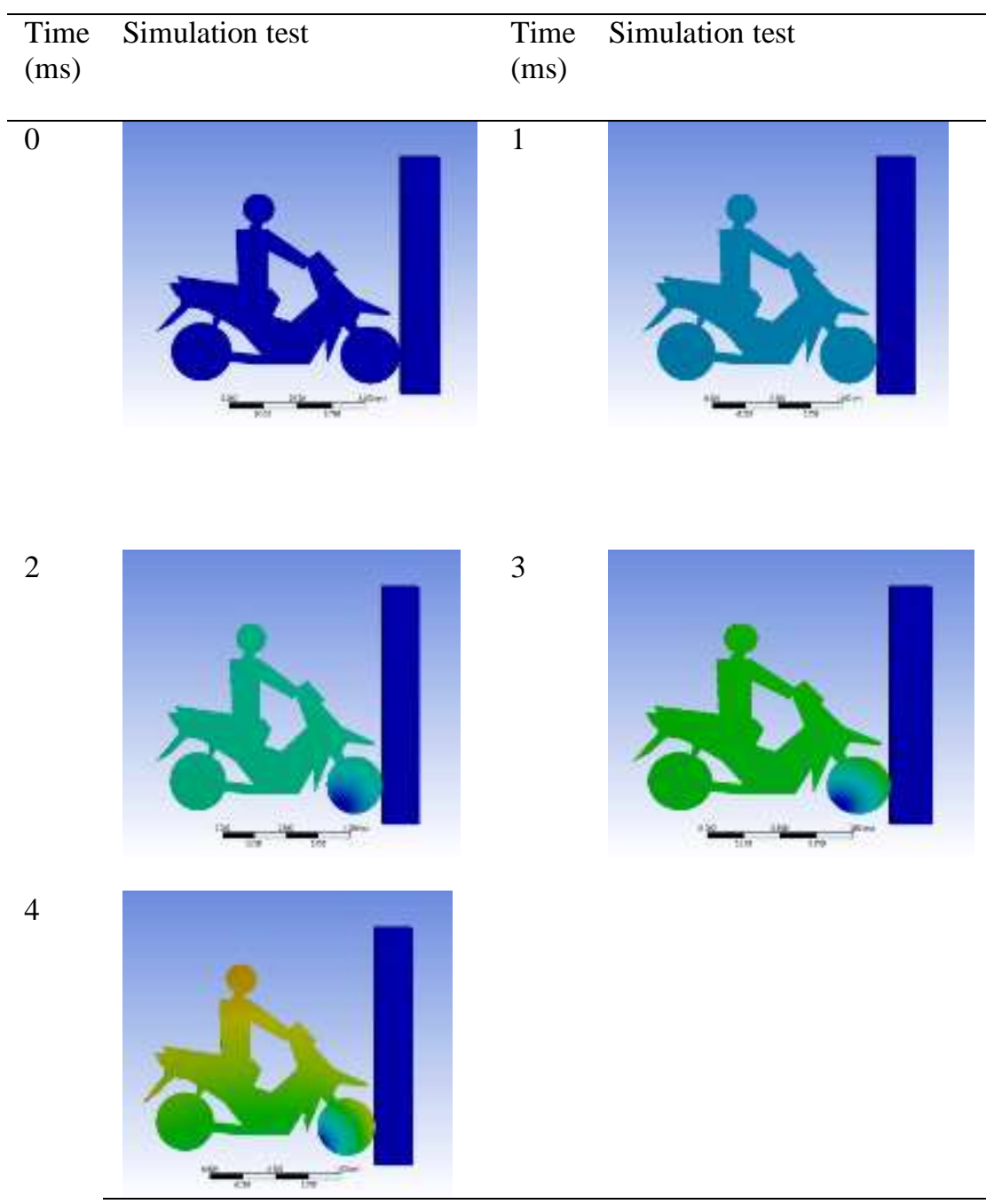

Fig. 6 - The simulation test in velocity $5.6 \mathrm{~m} / \mathrm{s}$

For test 2, the process of the simulation is represented by difference velocity. The purposed of the test is comparing the displacement of the specified part to the difference of velocity in fixed time. The two new velocity are $22.22 \mathrm{~m} / \mathrm{s}$ and $38.889 \mathrm{~m} / \mathrm{s}$ which the new velocity are middle and maximum speed of the motorcycle. The new velocity is also applied to the body of motorcycle and dummy rider at z-direction. For the duration time impact is from $0 \mathrm{~ms}$ to 4 $\mathrm{ms}$ and been recorded for every $1 \mathrm{~ms}$ for seen the displacement which happen during impact. Fig. 7 is shown the simulation test of dummy with motorcycle in velocity $22.22 \mathrm{~m} / \mathrm{s}$ and Fig. 8 shown the simulation test of dummy with motorcycle in velocity $38.89 \mathrm{~m} / \mathrm{s}$.

Fig. 7 - The simulation test in velocity $22.22 \mathrm{~m} / \mathrm{s}$

\begin{tabular}{llll}
\hline $\begin{array}{l}\text { Time } \\
(\mathrm{ms})\end{array}$ & Simulation test & $\begin{array}{l}\text { Time } \\
(\mathrm{ms})\end{array}$ & Simulation test \\
\hline 0 & 1
\end{tabular}


2

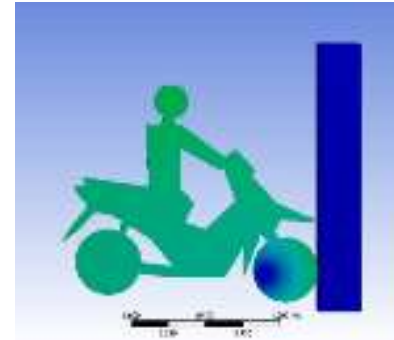

4

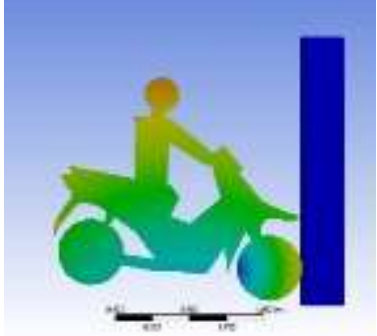

3

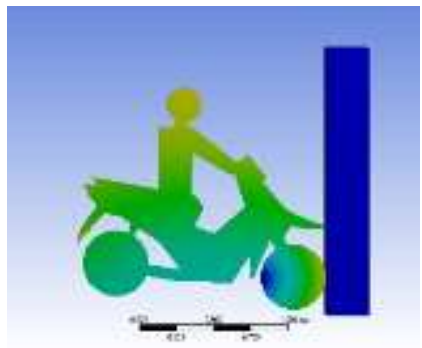

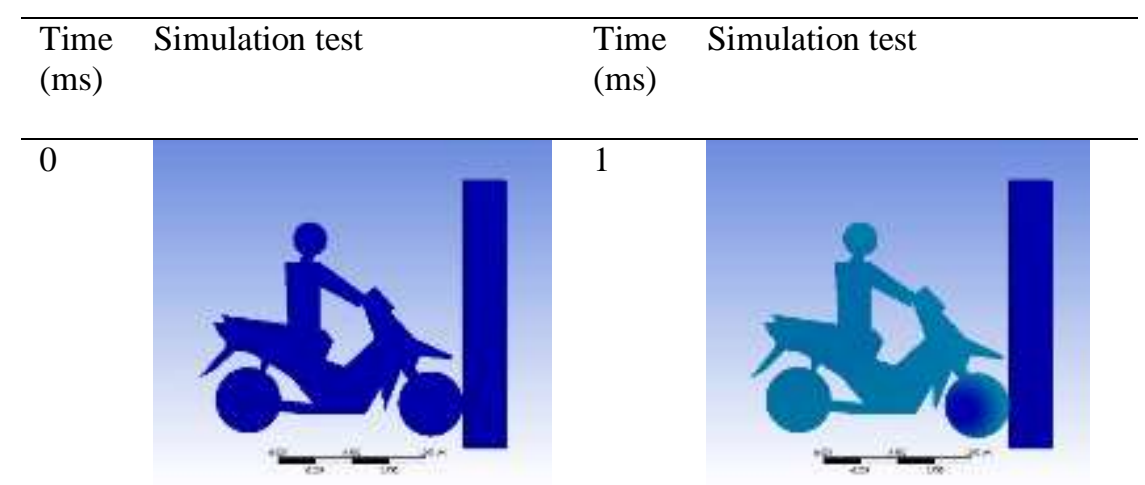

2

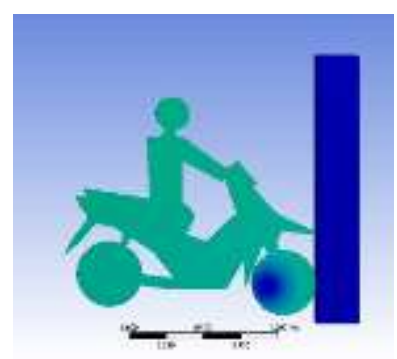

3

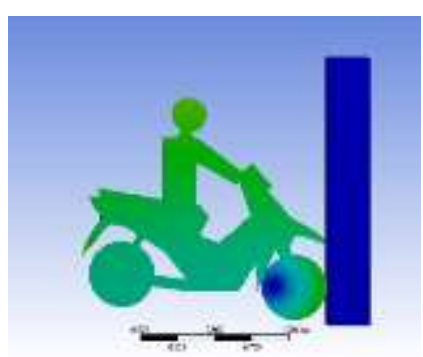

4

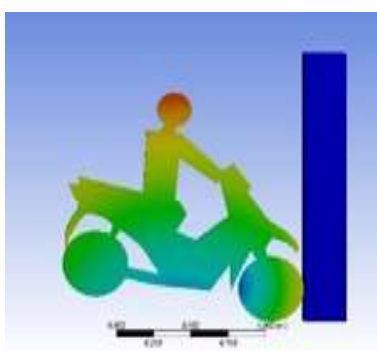

Fig. 8 - The simulation test in velocity $38.89 \mathrm{~m} / \mathrm{s}$ 
According to the Fig. 6, Fig.7 and Fig.8, It can be shown that the dummy is crash forward to wall. Besides that, the tyre of motorcycle also deformed during the impact. The landing direction of the dummy is forward to the wall. For the observation, the deformation of the motorcycle is increase while the increase of velocity. Other than that, the reaction kinematic of the dummy from the motorcycle is also increase while the velocity is increase. This result agreed well with the result from experimental result Hamzah et al. (2014).

\subsection{Graph of Analysis of Displacement}

Fig. 9 is the graph shown the displacement against time during the dummy rider and motorcycle impact with the wall. The test is recorded to $5.6 \mathrm{~m} / \mathrm{s}$ to $38.89 \mathrm{~m} / \mathrm{s}$. From the graph, the maximum displacement occurred at velocity $38.89 \mathrm{~m} / \mathrm{s}$ with $0.04 \mathrm{~m}$ of displacement. Then, the minimum displacement occurred at velocity $5.6 \mathrm{~m} / \mathrm{s}$ with $0.005 \mathrm{~m}$ of displacement. According to the graph, the displacement is increase while the velocity is increase. Thus, the increased of velocity is increase the fatal of human body. In a normal case, the injuries like abrasion, laceration and contusions will happen during the collision (RoSPA, 2017). If the rider collided in high velocity the serious injure will happen. So, the death is due to the increasing velocity because motorcycle is no airbags and no safety belts. To prevent and to reduce the harm, the rider should wear the helmet and any protection product for the limbs. The most important thing is the rider behaviour, they should ride their motorcycle in safety mode and follow the rules in the road to avoid the accident

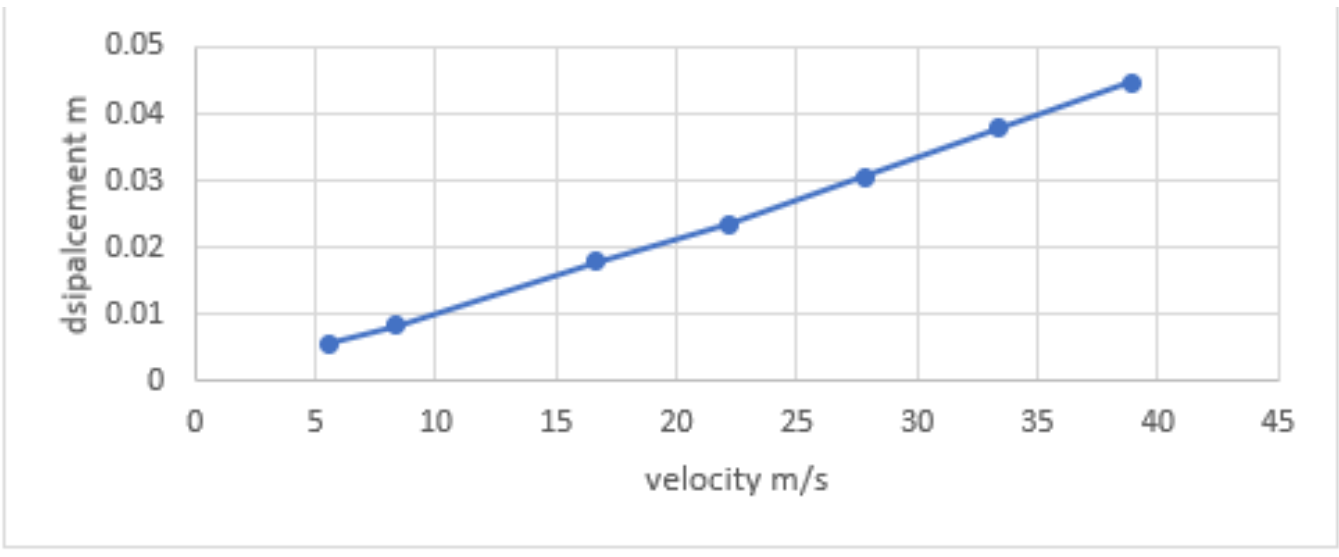

Fig. 9 - The graph of displacement against velocity

\subsection{Graph of Analysis of Energy}

Fig. 10 show the graph of energy summary of the deformation. According to the graph, the velocity of this simulation is $5.6 \mathrm{~m} / \mathrm{s}$. The kinetic energy shows the maximum point at 0s with $7333.6 \mathrm{~J}$ of energy and the minimum point at $4 \mathrm{~ms}$ with value $2000 \mathrm{~J}$. These shows that, the kinetics energy is decreasing because the impact at $4 \mathrm{~ms}$ and the kinetic energy start increasing because bounce from the impact. Then, the internal energy shows the maximum point at $4 \mathrm{~ms}$ with $5200 \mathrm{~J}$ of energy and the minimum point at $1.2 \mathrm{~ms}$ with value $-35.1 \mathrm{~J}$. These shows that, the internal energy of the body will start increasing because the impact until the impact at $4 \mathrm{~ms}$ the internal energy will start decreasing because of bounce from the impact. 


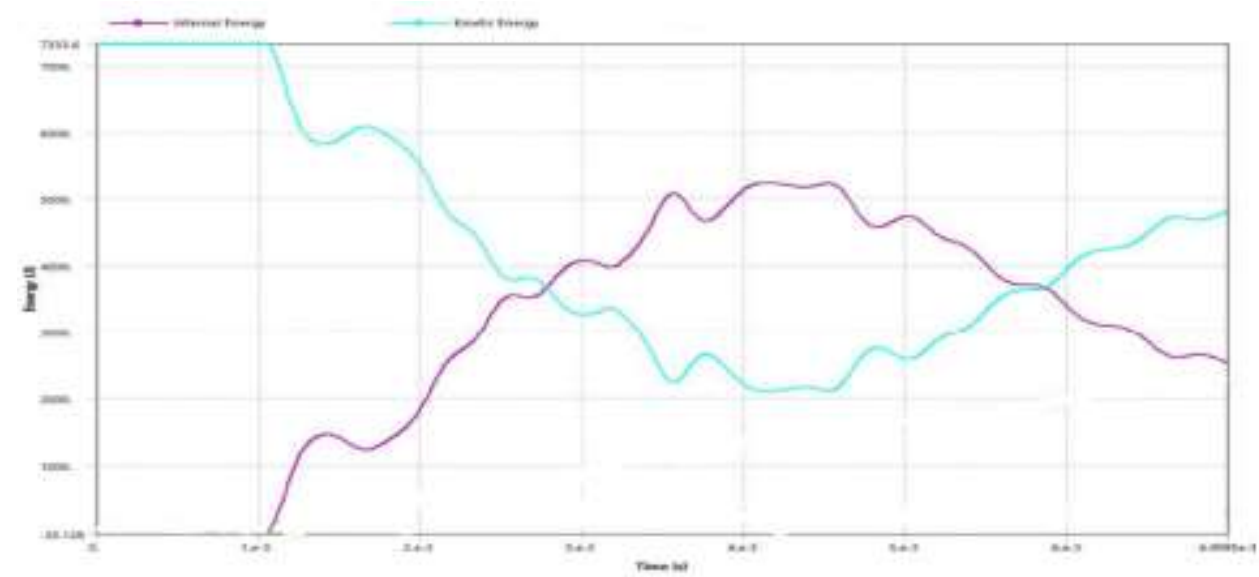

Fig. 10 - The graph of energy summary

\section{Conclusion}

Throughout this analysis, the computational simulation of the dummy rider with motorcycle had been developing in deformable body and kinematic body landing of rider during the collision. In the investigation of the displacement of frontal part which are tyre, rim and front cover set against difference velocity it was provided a good in result. To obtain the accurate result, the dummy rider model are full scale anthropometric test devices that simulate the dimensions, weigh proportions and articulation of the human body are usually instrumented to record data about the dynamic behaviour of the ATD in simulated motorcycle impacts. The benefit of the simulation process is producing the results without actual destructive testing of a dummy body and motorcycle. In this way, the test of simulation can be performed quickly and inexpensively in a computer. Using a simulation, problems can be solved before spending time and money on actual crash test. The great flexibility of printed output and graphical display enable designers to solve some problems what that would have been nearly impossible without the help of the computer. The application of the crash simulation is used to investigate the safety of the rider during impacts on the front end. According to the result, invent or improve the safety devices for the driver. The crash simulation can also be used to assess injury to rider hit to a car of pedestrians.

\section{Acknowledgement}

The authors would also like to thank the Faculty of Mechanical and Manufacturing Engineering, Universiti Tun Hussein Onn Malaysia for its support.

\section{References}

[1] Abdul Manan, M. M. \& Várhelyi, A. Motorcycle fatalities in Malaysia. (2012). International Association of Traffic and Safety Sciences Res., vol. 36, no. 1, pp. 30-39. doi: 10.1016/j.iatssr.2012.02.005

[2] Al Makky, A. . Introduction to ANSYS CFX Part 1 First Edition, May, pp. 1-17, 2018

[3] Hamzah, A. , Rahman, M. K. A. , Ariffin, H., Solah, M. S. , Anwar, K \& Kassim., A. (2014). Motorcycle Structural Response in Simulated Vehicular Collision, Proceedings of International Crashworthiness Conference (ICR 2014). Kuala Lumpur, MALAYSIA. November 25-28, pp. 1-6

[4] Hussain, H., Ahmad Farhan, M. S. , Radin Umar, R. S. \& Dadang, M. M. (2005). Key Components of a Motorcycle-Traffic System. IATSS Res., vol. 29, no. 1, pp. 50-56. doi: 10.1016/s0386-1112(14)60118-7.

[5] Izumi, M. \&. Sonohara, M. (2008). Introduction to the Feature. Igaku Toshokan, vol. 55, no. 3, pp. $211-211$. doi: 10.7142/igakutoshokan.55.21

[6] Mario, M. et al., (2017). Development of a Motorcycle FE Model for Simulating Impacts into Roadside Safety Barriers. Transp. Res. Circ. E-C220, no. June, pp. 657-673

[7] Md Isa, M. H., Md Deros, B., Mohd Jawi, Z. \& Abu Kassim, K. A. (2016). An anthropometric comparison of current anthropometric test devices (ATDS) with Malaysian adults. Malaysian J. Public Heal. Med., vol. 2016, no. Specialissue, pp. 15-21

[8] Mongiardini, M., Bill, W., Raphael, H., Matthew, M., Chris, Alexander, b., \& Peter, R. (2017). Development of a Motorcycle FE Model for Simulating Impacts into Roadside Safety Bar riers. Transportation Research Circular E-C220, (no. June) : 657-73

[9] RoSPA, RoSPA Road Safety Research. November, pp. 1-15, 2017, [Online]. Available: https://www.rospa.com/rospaweb/docs/advice-services/road-safety/motorcyclists/common 
[10] Teretskyi, D. \& Provotar, A,. (2017). Computational Models for Business and Engineering Domains ObjectOriented Dynamic Networks, no. December

[11] Waluyo. A.S, Instructors Manual Finite Element Method Laboratory Sessions, July, pp. 200, 2010

[12] Zainal Abidin, A. N. S, Mohd Faudzi S. A., Lamin. F., \& Abdul Manap A. R. (2017). MIROS Crash Investigation and Reconstruction Annual Statistical Report 2007 - 2010 